\title{
Corrigendum
}

\section{Corrigendum to "A Distributed Relation Detection Approach in the Internet of Things"}

\author{
Weiping Zhu $\mathbb{D}^{1},{ }^{1}$ Hongliang $\mathrm{Lu}^{2,3}$ Xiaohui Cui, ${ }^{1}$ and Jiannong $\mathrm{Cao}^{3}$ \\ ${ }^{1}$ International School of Software, Wuhan University, Wuhan, China \\ ${ }^{2}$ Science and Technology on Parallel and Distributed Processing Laboratory, National University of Defense Technology, \\ Changsha, China \\ ${ }^{3}$ Department of Computing, Hong Kong Polytechnic University, Kowloon, Hong Kong \\ Correspondence should be addressed to Weiping Zhu; cswpzhu@gmail.com
}

Received 21 January 2019; Accepted 27 January 2019; Published 7 March 2019

Copyright (C) 2019 Weiping Zhu et al. This is an open access article distributed under the Creative Commons Attribution License, which permits unrestricted use, distribution, and reproduction in any medium, provided the original work is properly cited.

In the article titled "A Distributed Relation Detection Approach in the Internet of Things" [1], the order of the research funders was incorrect. The order should be corrected in Acknowledgements as follows:

This research was supported in part by the National Natural Science Foundation of China (no. 61502351), Outstanding Young Academic Talents Start-Up Funds of Wuhan University (no. 216-410100004), Fundamental Research Funds for the Central Universities of China (no. 2042015kf0042), and Natural Science Foundation of Hubei, China (no. 2015CFB340).

\section{References}

[1] W. Zhu, H. Lu, X. Cui, and J. Cao, "A distributed relation detection approach in the internet of things," Mobile Information Systems, vol. 2017, Article ID 4789814, 14 pages, 2017. 


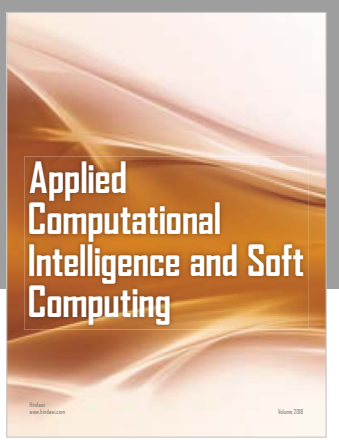

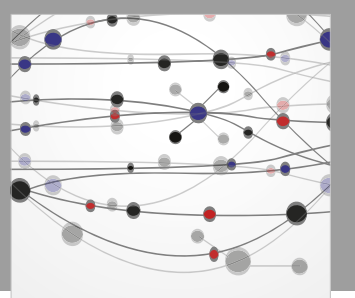

The Scientific World Journal
Submit your manuscripts at

Computing
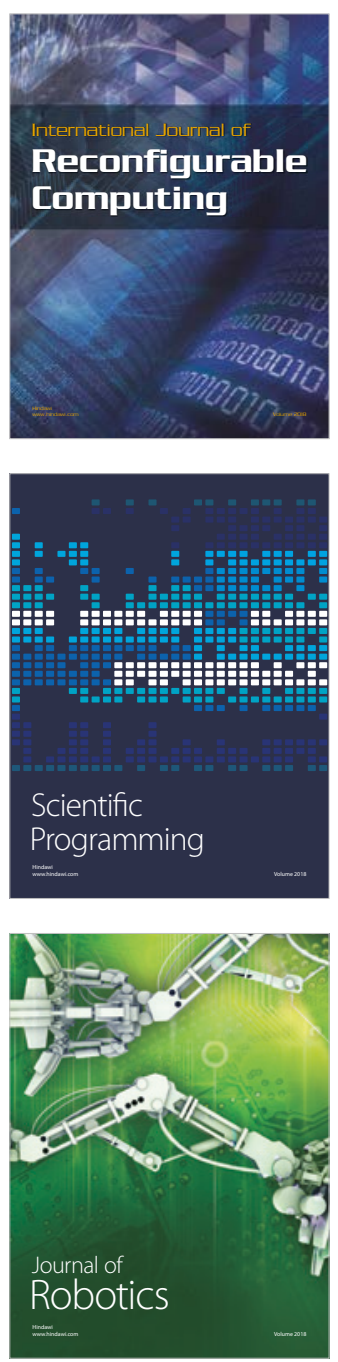

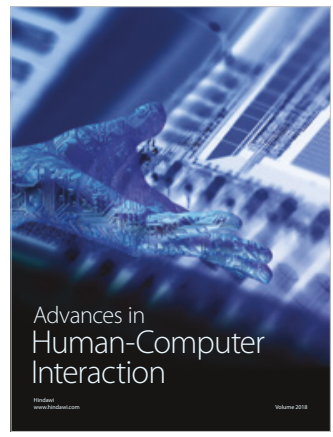

Human-Compute

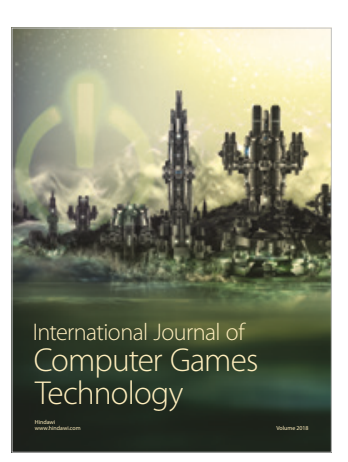

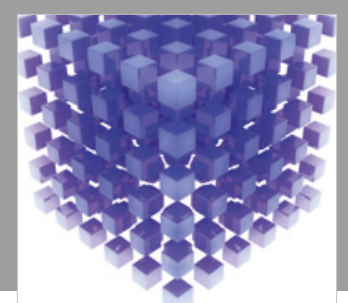

Mathematical Problems in Engineering

\section{Engincering}
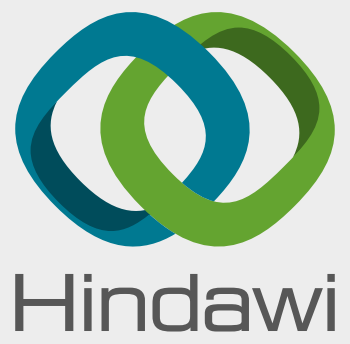

www.hindawi.com
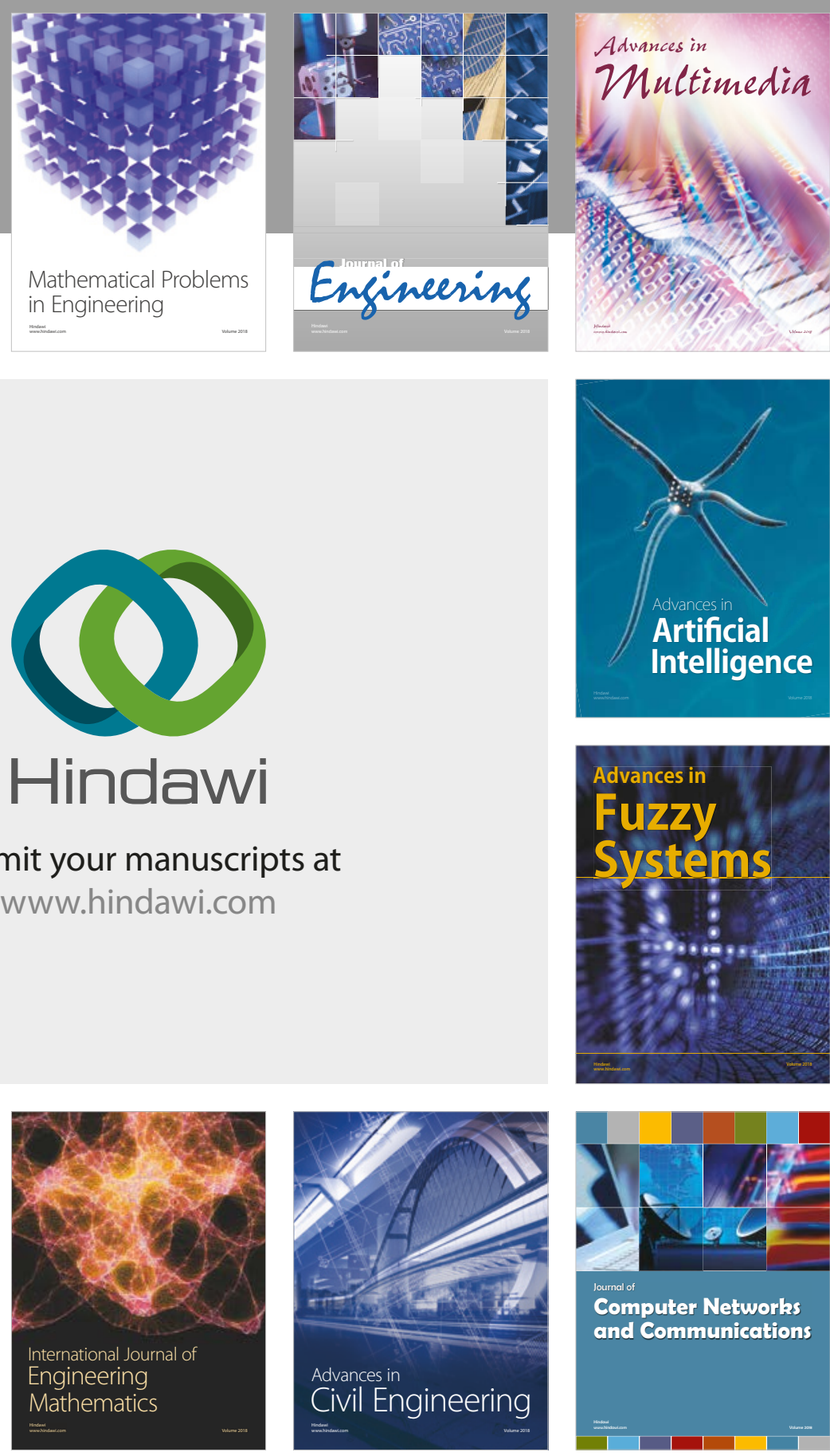

Computer Networks and Communications

Multimedia
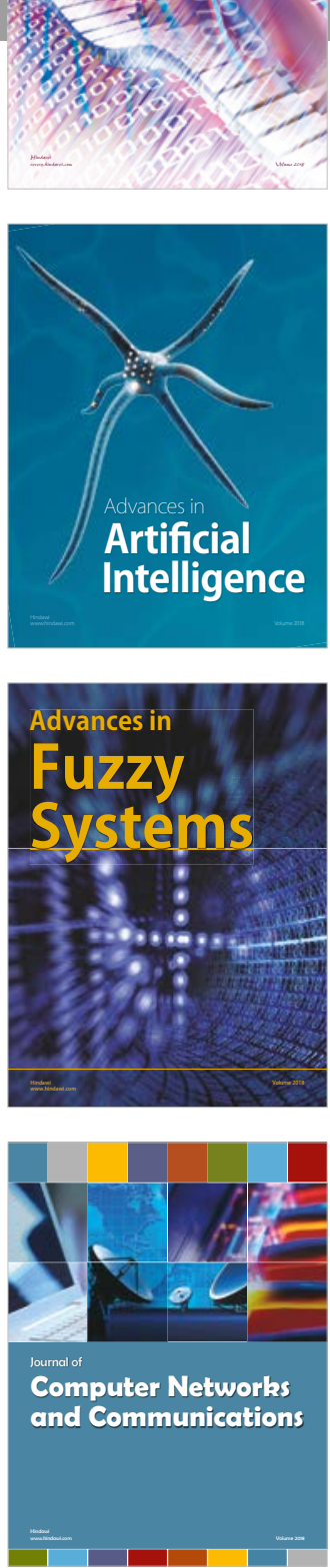

Advances in

Modelling \&

Simulation

in Engineering

interaction

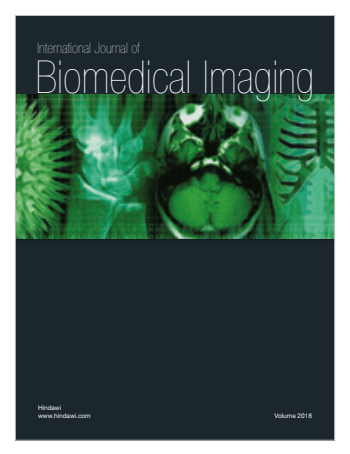

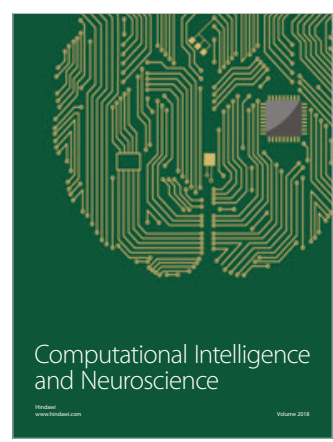

